\title{
The genetic basis of host plant adaptation in the brown planthopper (Nilaparvata lugens)
}

\author{
M. SEZER* \& R. K. BUTLINं \\ Department of Biology, The University of Leeds, Leeds LS2 9J T, U.K.
}

\begin{abstract}
We studied the genetic architecture of host plant adaptation in two populations of brown planthopper Nilaparvata lugens (Homoptera: Delphacidae): one feeding on cultivated rice Oryza sativa and the other feeding on a weed grass Leersia hexandra. Proportional weight change, survival and development time of inbred Leersia- and rice-feeding lines, $\mathrm{F}_{1}, \mathrm{~F}_{2}$, and backcross classes have been examined. Most of the performance differences among populations seem to be controlled by a few genes. Dominance of rice population alleles over Leersia population alleles was quite strong, and there was evidence for epistatic interaction. Nymphto-adult survival of the cross classes was found to be highly correlated with mean weight change of the adults. These results are discussed in relation to a presumed host shift from Leersia to rice.
\end{abstract}

Keyw ords: host-associated performance, hybridization, Nilaparvata lugens, quantitative genetics, sympatric speciation.

\section{Introduction}

Many studies on insect-plant interactions have found that herbivorous insects have the evolutionary potential to alter their host range either by narrowing it to exclude hosts, by broadening it to include new hosts, or by shifting to a novel host (Via, 1990; Thompson \& Pellmyr, 1991). Although this suggests the possibility of either inclusion or exclusion, it is notable that most phytophagous insects are monophagous, and many others that are polyphagous overall show specialization on locally abundant hosts (Via, 1989). The level of specialization is considered to influence the distribution and population structure of a species and the origin of new species (Jaenike, 1990). The importance of specialization has focused much research on the factors leading to host specificity in insect populations. However, the genetic basis of host plant use by insects has received less attention. Genetic analysis can provide very valuable information, applicable to a broad array of studies of insect-plant relationships, including theoretical interest in the development of

*Correspondence and present address: Metin Sezer, Gaziosmanpasa Universitesi, Ziraat Fakultesi, Zootekni Bolumu, Tokat, Turkey.

$\dagger$ †-mail: r.k.butlin@leeds.ac.uk specialization and its role in speciation, and the practicalities of agricultural plant protection (Futuyma \& Peterson, 1985; Jaenike, 1990; Via, 1990).

Genetic variation, and the mode of inheritance of host preference and host-associated performance, dictate the potential for evolutionary changes that increase the fitness of individuals on a host (Futuyma \& Peterson, 1985; Via, 1990). Numerous studies show that life history and performance characters vary within and among herbivorous insect populations and have considerable potential for response to selection (see reviews by Futuyma \& Peterson, 1985; Via, 1990; Jaenike \& Holt, 1991).

Relative to demonstrations of genetic variation within and among populations, few attempts have been made to investigate the genetic architecture of host-associated performance (Futuyma \& Peterson, 1985; Via, 1990). Three basic patterns for the genetic basis of reproductive barriers were reviewed by Templeton (1981): (i) with many segregating units each of small effect; (ii) with one or a few major segregating units, commonly with many epistatic modifiers; and (iii) with complementary or duplicate pairs of loci. There is little consistency in the results of hybridization experiments and a range of genetic architectures has been observed, as illus- 
trated by the following examples. It has been shown that the ability of biotypes of the Hessian fly Mayetiola destructor to survive on wheat varieties is controlled by single recessive alleles (Hatchett \& Gallun, 1970). A hybridization experiment with Drosophila sechellia, which specializes on the fruit of Morinda citrifolia, and the generalist D. simulans (R'kha et al., 1991) suggests that the high tolerance of $D$. sechellia to toxic effects of Morinda behaves as a dominant genetic trait, whereas early mortality of embryos is a maternally inherited character. Bierbaum \& Bush (1990) studied sibling species of Rhagoletis fruit flies from apple orchards (R. pomonella) and highbush blueberries ( $R$. mendax) in Michigan and found that genes from $R$. mendax associated with high larval-to-pupal survival have a dominant effect in reducing viability on apple. However, maternal inheritance was the most likely explanation for the viability of hybrid progenies reared on blueberries.

Extrinsic barriers to gene flow may divide a population into independently evolving subpopulations. Pre- and postzygotic isolation can then arise among locally adapted races within a species as a result of gradually accumulated genetic differences. Because of the gradual divergence of the populations, polygenic architecture is most likely. On the other hand, parts of a single breeding population may adapt to different niches or habitats without allopatry, leading to the evolution of premating reproductive isolation among subpopulations (Templeton, 1981; Rice \& Hostert, 1993). In this model, intense continuous disruptive selection causes polymorphism. Gene flow among subpopulations, which is potentially strong because of the lack of extrinsic barriers to gene flow, must be weaker than selection, for differentiation to occur. Disruptive selection may directly or pleiotropically yield isolation barriers. In these circumstances, it is most likely that a few major genes govern the rapid divergence. There is some evidence for host plant shifts that have followed this sympatric pathway (Tavormina, 1982; Tauber \& Tauber, 1989; Bush, 1995). Thus sympatric host shifts are predicted to be associated with genetic determination of host-associated preference or performance by a few genes, whereas allopatric divergence of host use will tend to have a polygenic architecture.

The number of genes controlling the traits determining host plant use is the most important aspect of the genetic architecture of host adaptation to be examined. A study of sawflies belonging to the Neodiprion abietis complex in Nova Scotia showed that some morphological characters, development time and feeding patterns were influenced by one or a few dominant genes (Knerer \& Atwood, 1972). On the other hand, some other traits such as hatching and emergence time, body size and fecundity were under polygenic control. The aphid Cryptomyzus galeopsidis was also reported to display polygenic determination of host-associated reproductive performance (Guldemond, 1990). However, most studies have not been taken far enough in terms of the hybrid generations investigated, to provide meaningful analyses of genetic architecture.

\section{Study organism}

The brown planthopper Nilaparvata lugens is a major pest of rice throughout India and south-east Asia. It can use many rice varieties as a host plant and can adapt rapidly to resistant varieties (Den Hollander \& Pathak, 1981). Throughout its range, morphologically indistinguishable populations feed on the semiaquatic weed Leersia hexandra (Heinrichs \& Medrano, 1984; Claridge et al., 1985). The two forms differ in mating signals and DNA sequences (Jones et al., 1996). Homogametic mating preferences in the laboratory, and lack of intermediate mating signals in field samples suggest that rice- and Leersia-feeding populations may represent sibling species, although low levels of gene exchange cannot be excluded at present (Claridge et al., 1985, 1988; Butlin, 1993, 1996; Trickett, 1995).

Nilaparvata lugens populations appear to contain abundant polygenic variation for host-associated traits. There is evidence that $N$. lugens populations differ both in consumption rates and in efficiency of utilization of rice cultivars (Den Hollander \& Pathak, 1981; Claridge et al., 1985). These physiological and behavioural strains are referred to as 'biotypes'. A series of experiments on development of biotypes demonstrated that the brown planthopper can develop biotypes which survive and reproduce on previously resistant rice varieties within 10 generations by continuous rearing in isolation on those varieties. Crosses between any two biotypes demonstrated that the hybrid offspring always showed lower performance than did their better parent, indicating trade-offs between performance on different varieties.

Although much work has been accumulated on rice biotypes, the genetic basis of adaptation to rice as opposed to Leersia is not known. Here we report the results of a study on the inheritance of hostassociated performance in crosses between rice- and Leersia-feeding stocks. Analysis of oviposition

(C) The Genetical Society of Great Britain, Heredity, 80, 499-508. 
preference data for these crosses will be presented elsewhere.

\section{Materials and methods}

\section{Stocks and crosses}

Stock populations of brown planthopper were derived from a collection made at Dhanbad, Bihar, India in 1989 from rice and a collection made at Bogor, Java, Indonesia in 1990 from Leersia hexandra. Stocks were provided by Professor M. F. Claridge at the University of Wales, Cardiff. Rearing conditions have been described previously by Butlin (1993, 1996) and Trickett (1995). Although the long period under laboratory conditions will have resulted in some inbreeding, six inbred lines were derived from each stock population of $N$. lugens by at least seven generations of sib-mating in order to minimize within-line genetic variation before making crosses between lines. Two of the lines were chosen, on the basis of low variability of performance on their original host plant, to carry out the main experiments. The inbred lines were separately reared on their respective host plants, $L$. hexandra cuttings (individual stems rooted for 7-10 days, derived from plants collected in Indonesia with the planthoppers) and young plants (4-5 weeks old) of TN1 (a brown planthopper-susceptible rice variety, originally obtained from the International Rice Research Institute), in $2 \times 15 \mathrm{~cm}$ glass boiling tubes, with $4-5 \mathrm{~cm}$ depth of tap water and a cotton wool stopper to prevent the planthoppers from escaping.

Crosses were made by placing one male and one female in a boiling tube containing both Leersia and TN1 stems. Parental lines were hybridized to produce reciprocal $\mathrm{F}_{1}$ crosses (denoted by $\mathrm{R} \times \mathrm{L}$ and $\mathrm{L} \times \mathrm{R}$, female parent first). Four classes of $\mathrm{F}_{2}$ crosses were carried out using males and females of the $F_{1}$ crosses $(\mathrm{RL} \times \mathrm{RL}, \mathrm{RL} \times \mathrm{LR}, \mathrm{LR} \times \mathrm{LR}, \mathrm{LR} \times \mathrm{RL})$. All eight possible first backcrosses were also conducted $(\mathrm{RL} \times \mathrm{R}, \mathrm{RL} \times \mathrm{L}, \mathrm{R} \times \mathrm{RL}, \mathrm{L} \times \mathrm{RL}$, $\mathrm{LR} \times \mathrm{R}, \mathrm{LR} \times \mathrm{L}, \mathrm{R} \times \mathrm{LR}, \mathrm{L} \times \mathrm{LR})$. Some of the newly hatched nymphs of each $F_{1}, F_{2}$ and backcross progeny were left in tubes that contained both host plants and reared to adulthood for use in performance experiments.

Tubes were checked in the first hour of the 12:12 light:dark cycle and all adults that had become mature during the dark period were removed. Tubes were checked for new adults during the light period at $3 \mathrm{~h}$ intervals to obtain individuals of precisely known age. Newly emerged female adults were placed on stems of Leersia or rice individually. To reduce variation caused by environment and handling, every day one or two females from each class of cross on each host plant were assessed simultaneously. Each individual was weighed and $72 \mathrm{~h}$ later the measurement was repeated.

Ten replicates of five nymphs each from each class of cross were placed on either Leersia or rice plants for measurement of nymph-to-adult survival and development time. The date of appearance of the first adult and number of adults were recorded.

\section{Analysis}

Data were analysed using GENSTAT 5 (GENSTAT, 1987) and spss (Norusis, 1993) statistical software. Performance was expressed as the proportional weight change relative to initial weight in the $72 \mathrm{~h}$ following transfer to the test host. Analyses of nymph-to-adult survival were carried out with values for the number of nymphs surviving, out of five, in 10 replicates per class of cross. The performance data were examined on both the linear scale and other possible scales (log and square root transformations), but neither of the alternative scales improved the fit to simple genetic models. Hence, this report only includes the linear scale analyses. There is some evidence that the performance data are truncated by death of individuals falling below a minimum weight. We were unable to obtain good fits to singly truncated normal distribution models, presumably because the amount of data required to estimate an unknown truncation point is very large. This does not appear to be a serious problem for the performance data on rice but it may be the reason for our inability to fit genetic models to the data for performance on Leersia (see below).

Mather's A, B and C scaling tests and Cavalli's joint scaling test were used to assess the significance of the additive-dominance, maternal, and non-allelic interaction components of genetic variation in performance (Mather \& Jinks, 1982). The most suitable models were identified by testing for adequacy of submodels fitted in the absence of one component. Effective numbers of loci, $n$, contributing to the variances of characters, and their standard errors, were estimated using formulae suggested by Wright (1968) and expanded by Lande (1981). In addition to this method, a maximum likelihood approach, described by Butlin (1996), was used to estimate simultaneously not only the number of loci involved but also the degree of dominance, $h$, and the environmental variance $V_{\mathrm{e}}$. 


\section{Results}

\section{Inheritance of performance on rice}

There were significant differences in performance on rice among cross classes (ANOVA; MS among $=3.01$; $F_{15,644}=13.76, P<0.01$ ), but performance on rice was not significantly different between reciprocal crosses $(P>0.05)$. This similarity in performance among the reciprocal crosses suggests that maternal/cytoplasmic effects did not contribute to the difference in weight gain between the two populations and was confirmed by Cavalli's joint scaling test (Mather \& Jinks, 1982) $\left(\chi_{4}^{2}=10.13, P<0.05\right)$. Therefore reciprocal crosses were combined (Table 1; Fig. 1). The differences among cross classes remained highly significant $\quad\left(\mathrm{MS} \quad\right.$ among $=8.77 ; \quad F_{5,654}=40.79$, $P<0.01)$.

\section{Scaling and joint scaling test results}

To test the adequacy of the additive-dominance genetic model, $\mathrm{A}, \mathrm{B}$ and $\mathrm{C}$ scaling test values were calculated for performance on rice (Mather \& Jinks, 1982) (all results are given as estimate \pm SE: $A=-0.044 \pm 0.096, \quad B=-0.86 \pm 0.11 \quad$ and $C=-0.0016 \pm 0.2$ ). The $A$ and $C$ values were not significantly different from zero. However, the significant $B$ value indicates that this model is not a completely adequate explanation of the data. The result of the joint scaling test was $\chi_{6}^{2}=11.22$, $0.1>P>0.05$ (Table 2). The additive-dominance model could be judged adequate according to this result but it is marginal and the addition of a contribution from non-allelic interactions improves the fit significantly (Table 2). All three non-allelic interaction components had large estimated values, but also large standard errors, and the other components of the six-parameter model were difficult to interpret. We tried to fit five-parameter models in the absence of one of the non-allelic interaction components. In these analyses, elimination of the heterozygote $\times$ heterozygote interaction resulted in the best fit and subsequently exclusion of the nonsignificant homozygote $\times$ homozygote interaction resulted in the best-fitting four-parameter model. As indicated before, maternal/cytoplasmic effects were also found to make no significant contribution to the genetic basis of performance $\left(\chi_{4}^{2}=10.1, P<0.05\right)$. In spite of the fact that the $m,[d]$ and $[h]$ values computed were quite similar to the additivedominance model, maternal components $[\mathrm{dm}]$ and $[\mathrm{hm}]$ were not significantly different from zero (single-sample $t$-test; $t=0.66, t=0.75, P>0.05$ ). The results indicate a strong degree of dominance in weight gain on rice plants with the alleles causing higher weight gain (from the rice-feeding parent) dominant to alleles which reduce performance on rice. Additionally, non-allelic interactions apparently play some modifying role for the variation of this trait.

\section{Effective number of genes}

Because the above analyses revealed only weak epistatic effects, we proceeded to calculate the effective number of loci influencing performance. Contrary to expectations from studies on other insect herbivores, our results indicate that a relatively small number of loci is responsible for the difference between stocks in ability to feed on rice

Table 1 Comparison of mean performance of Nilaparvata lugens on rice and Leersia plants with reciprocal crosses pooled

\begin{tabular}{|c|c|c|c|c|c|c|c|c|}
\hline \multirow[b]{2}{*}{ Mating } & \multicolumn{4}{|c|}{ Performance on rice } & \multicolumn{4}{|c|}{ Performance on Leersia } \\
\hline & $N$ & Mean & $\mathrm{SD}$ & $\mathrm{CM}$ & $N$ & Mean & SD & $\mathrm{CM}$ \\
\hline $\mathrm{P}_{1}(\mathrm{R})$ & 50 & 0.914 & 0.347 & $\mathrm{a}$ & 48 & -0.073 & 0.135 & $\mathrm{c}$ \\
\hline $\mathrm{B}_{1}(\mathrm{BR})$ & 194 & 0.801 & 0.475 & $\mathrm{a}$ & 187 & -0.039 & 0.191 & $\mathrm{c}$ \\
\hline $\mathrm{F}_{1}$ & 91 & 0.732 & 0.435 & $\mathrm{ac}$ & 87 & 0.012 & 0.210 & $\mathrm{bc}$ \\
\hline $\mathrm{F}_{2}$ & 166 & 0.607 & 0.518 & $\mathrm{c}$ & 170 & -0.025 & 0.206 & $\mathrm{c}$ \\
\hline $\mathrm{B}_{2}(\mathrm{BL})$ & 115 & 0.225 & 0.481 & $\mathrm{~b}$ & 119 & 0.096 & 0.226 & $\mathrm{~b}$ \\
\hline $\mathrm{P}_{2}(\mathrm{~L})$ & 44 & 0.049 & 0.285 & $\mathrm{~b}$ & 50 & 0.473 & 0.345 & $\mathrm{a}$ \\
\hline
\end{tabular}

$N$, the number of individuals; Mean, the average proportional weight change relative to initial weight; $\mathrm{SD}$, the standard deviation; $\mathrm{CM}$, the comparison of means (means with the same letter are not significantly different at $\alpha=0.05$ by Tukey's studentized range tests). 
plants. All four estimates based on the formulae from Lande (1981) are close to one, although the $n_{3}$ estimate is clearly not reliable (Table 3 ). If Wright's (1968; eqn 15.11, p. 384) correction factor of 1.5 for complete dominance is applied, the estimates are
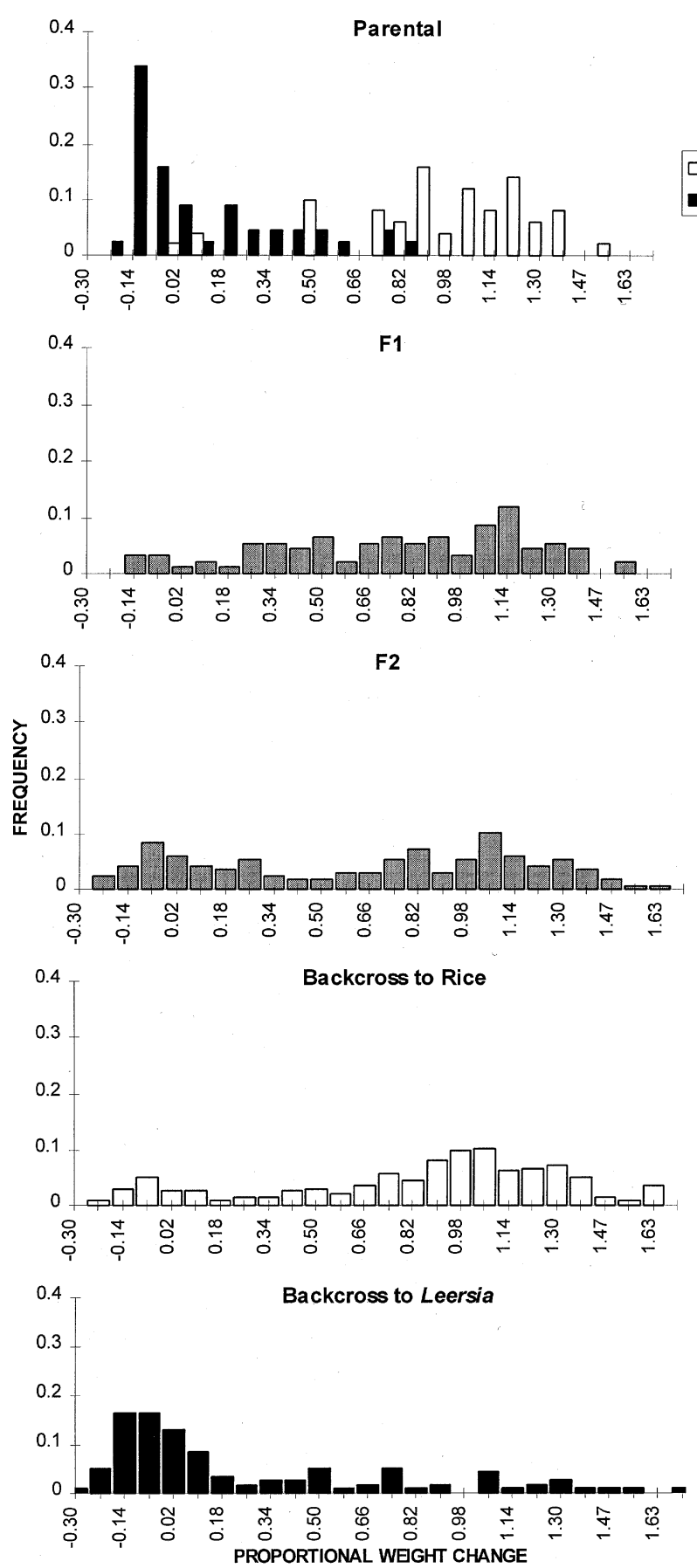

Fig. 1 Frequency distribution of performance of the parental, $\mathrm{F}_{1}, \mathrm{~F}_{2}$, BR (backcross to rice) and BL (backcross to Leersia) classes of Nilaparvata lugens on rice plants. closer to two loci. This assessment is supported by maximum likelihood estimation. Two alternative models have been fitted (based on the data in Table 1): with estimation of different parental variances or with directional dominance. In both cases the maximum likelihood estimate is two loci (Table 3). Comparison of the estimated directional dominance $h(1=$ complete dominance in direction of $\mathrm{P}_{1}, 0.5=$ no dominance, and $0=$ complete dominance in direction of $\mathrm{P}_{2}$ ) with the results of the joint scaling test indicate complete agreement: $h=0.66 \pm 0.072$ if $n=1$, and $h=0.76 \pm 0.099$ if $n=7$. These $h$ values can be expressed as deviations from the mid-parent values which are 0.16 and 0.26 , respectively; close to the estimated values from the joint scaling test, which were between 0.23 and 0.29 ignoring the six-parameter model.

Heritability of performance on rice has been calculated as 0.30 (narrow sense) and 0.37 (broad sense), $D$ (combined additive variance $)=0.162, H$ (combined dominance variance $)=0.0692$, using the environmental variance estimate of 0.17 from the maximum likelihood approach.

\section{Inheritance of performance on Leersia}

Compared to the rice stock reared on rice, the Leersia stock performed relatively less well on Leersia plants. Similarly, the proportional weight gain of rice stock individuals on Leersia was lower than for Leersia parental individuals on rice. It seems that Leersia may be a less nutritious food source overall (Fig. 2). These observations are mirrored in the survival and development time data (see below). As with the performance data on rice, there were significant differences among cross classes on Leersia (ANOvA; MS among $=0.87$; $\left.F_{15,645}=18.9, \quad P<0.01\right)$, but significant differences were not detected between any of the reciprocal crosses. In general, the cross classes that achieved high weight gain on one plant had low weight gain on the other host or vice versa. Overall, the correlation between the performance on rice and Leersia over the means of cross classes was significantly negative: $r=-0.74, n=16, P<0.001$.

The scaling test results for the additive-dominance genetic model were $A=-0.29 \pm 0.068, B=$ $-0.019 \pm 0.041$ and $C=-0.526 \pm 0.094$. In this case, the $A$ and $C$ values are significantly different from zero. The joint scaling test (Table 4) also indicates that the additive-dominance model is not adequate for this part of the data $\left(\chi_{6}^{2}=38.09, P<0.01\right)$. As with the previous results for performance on rice, the additive-dominance plus non-allelic interaction 
Table 2 Estimated components of the cross mean performance for Nilaparvata lugens when reared on rice plants using additive-dominance, non-allelic interaction, and maternal-effect models

Additive-dominance and non-allelic interaction combination

Components Six parameter Five parameter Four parameter
Maternal and Additive-dominance Additive model additive-dominance model only combination Three parameter Two parameter Five parameter

\begin{tabular}{|c|c|c|c|c|c|c|}
\hline$m$ & $0.85 \pm 0.2$ & $0.41 \pm 0.09$ & $0.46 \pm 0.09$ & $0.46 \pm 0.03$ & $0.56 \pm 0.02$ & $0.47 \pm 0.03$ \\
\hline$[d]$ & $0.4 \pm 0.03$ & $0.43 \pm 0.03$ & $0.43 \pm 0.03$ & $0.46 \pm 0.03$ & $0.47 \pm 0.03$ & $0.45 \pm 0.05$ \\
\hline$[h]$ & $-0.9 \pm 0.48$ & $0.29 \pm 0.12$ & $0.23 \pm 0.12$ & $0.23 \pm 0.05$ & - & $0.23 \pm 0.06$ \\
\hline$[j]$ & $0.3 \pm 0.13$ & $0.24 \pm 0.13$ & $0.24 \pm 0.13$ & - & - & - \\
\hline$[i]$ & $-0.37 \pm 0.2$ & $0.06 \pm 0.1$ & - & - & - & - \\
\hline$[l]$ & $0.74 \pm 0.3$ & - & - & - & - & - \\
\hline$[d m]$ & - & - & - & - & - & $0.01 \pm 0.02$ \\
\hline$[\mathrm{hm}]$ & - & - & - & - & - & $-0.03 \pm 0.04$ \\
\hline Test statistics & $\chi_{3}^{2}=0.9$ & $\chi_{4}^{2}=6.3$ & $\chi_{5}^{2}=7.3$ & $\chi_{6}^{2}=11.22$ & $\chi_{7}^{2}=27.2$ & $\chi_{4}^{2}=\overline{10} .1$ \\
\hline$P$ & $0.9-0.5$ & $0.3-0.1$ & $0.3-0.1$ & $0.1-0.05$ & $<0.001$ & $0.05-0.01$ \\
\hline
\end{tabular}

$m$, mid-parent value; $d$, phenotypic difference between the two homozygotes and $m ; h$, departure in phenotype of heterozygote from $m ; i$, homozygote $\times$ homozygote interaction; $j$, homozygote $\times$ heterozygote interaction;

$l$, heterozygote $\times$ heterozygote interaction; $d m$, maternal components contributed by homozygous genotype; $h m$, maternal components contributed by heterozygous genotype.

combination was the best-fitting model. The estimated components suggested, from the six-parameter model, strong epistasis but little dominance, making interpretation of the results difficult (Mather \& Jinks, 1982). Unsuitability of the Leersia plant for feeding by most of the cross classes (Fig. 3) caused considerable mortality before the second measurement, and caused mean weight gain of some classes to be low and probably unrealistically similar (Fig. 2). We were unable to recover from this biased estimation of the mean performances, and thus estimate the genetic components, by assuming that the data followed singly truncated distributions (DePriest, 1983). Our conclusion is that truncation by mortality of the individuals that lose too high a proportion of their body weight prevents reliable estimation of the genetic components. In these circumstances, it is clearly impossible to proceed to estimation of the effective number of loci influencing performance on Leersia.

Table 3 Estimates of the effective number of loci influencing performance of Nilaparvata lugens on rice

\begin{tabular}{lclll}
\hline & & & \multicolumn{2}{c}{$\begin{array}{c}\text { Estimated parameters by maximum } \\
\text { likelihood model }\end{array}$} \\
\cline { 1 - 1 } \cline { 5 - 5 } $\begin{array}{l}\text { Method of } \\
\text { calculation }\end{array}$ & $\begin{array}{c}\text { Effective number } \\
\text { of loci } \pm \text { SE }\end{array}$ & & $\begin{array}{c}\text { Allowing directional } \\
\text { dominance }\end{array}$ & $\begin{array}{c}\text { Using different } \\
\text { parental variances }\end{array}$ \\
\hline & & $n=2(1-7)$ & $n=2(1-3)$ \\
$n_{1}$ & $1.179 \pm 0.632$ & & $m_{\mathrm{P} 1}=0.95 \pm 0.067$ & $m_{\mathrm{P} 1}=1.06 \pm 0.054$ \\
$n_{2}$ & $0.756 \pm 0.235$ & & $m_{\mathrm{P} 2}=-0.039 \pm 0.067$ & $m_{\mathrm{P} 2}=0.067 \pm 0.056$ \\
$n_{3}$ & $1.177 \pm 1.057$ & & $V_{\mathrm{e}}=0.17 \pm 0.017$ & $V_{\mathrm{P} 1}=0.213 \pm 0.046$ \\
$n_{4}$ & $0.557 \pm 0.185$ & & $h=0.72 \pm 0.087$ & $V_{\mathrm{P} 2}=0.16 \pm 0.05$ \\
\hline
\end{tabular}

$n_{1}$ and $n_{2}$ are the estimated numbers of factors using $\mathrm{F}_{2}$ variances; $n_{3}$ and $n_{4}$ estimations are based on backcross data (Lande, 1981). $n$, maximum likelihood estimate of effective number of loci (support limits); $m_{\mathrm{P} 1}$, mean performance of parent 1 (rice); $m_{\mathrm{P} 2}$, mean performance of parent 2 (Leersia); $V_{\mathrm{e}}$, environmental variance; $h$, directional dominance; $V_{\mathrm{P} 1}$, variance of parent $1 ; V_{\mathrm{P} 2}$, variance of parent 2 (see Butlin, 1996, for further details). 


\section{Survival and development time}

Significant differences in survival were detected among cross classes (Fig. 3 ; ANOVA; $F_{15,127}=8.31$, $P<0.01$ ), but again reciprocal crosses were not significantly different from each other. Neither of the parental stocks was able to survive from first instar
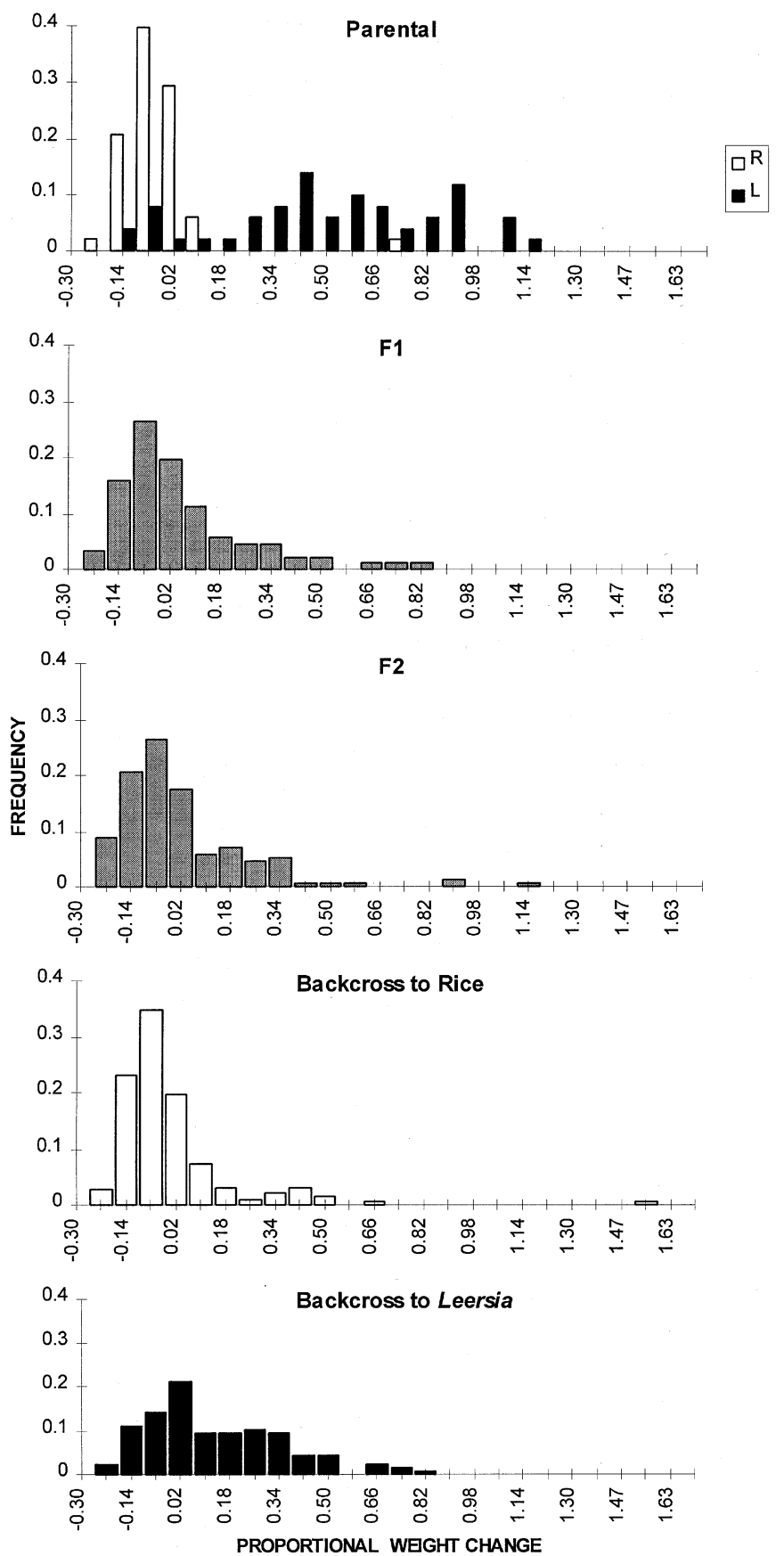

Fig. 2 Frequency distribution of performance of the parental, $F_{1}, F_{2}$, BR (backcross to rice) and BL (backcross to Leersia) classes of Nilaparvata lugens on Leersia plants. nymph to adult on the opposite host plant. The cross classes that lost weight or performed relatively less well on the alternative host plant also had lower survival rates on that host. As with the performance data, alleles from the rice parent are dominant over the alleles from the Leersia parent. The correlation between the mean proportional weight change and mean survival across the families was $r=0.93$ $(n=16)$ on rice and $r=0.92(n=16)$ on Leersia $(P<0.001$ in both cases). This suggests that these two characters have a common genetic basis and justifies our use of proportional weight change as a measure of performance. It also suggests that nymphal experience is unlikely to influence hostplant adaptation. The significant negative correlation between performance on rice and Leersia over class means was also repeated for survival: $r=-0.66$, $n=16, \quad P<0.005$. Male to female ratio was calculated using $F_{1}$ families, pooling all the individuals that survived on both host plants. The sex ratio of $0.48 \pm 0.066$ was not significantly different from $0.5\left(t_{19}=0.26\right)$. Hence, there is no indication of sex-linkage or Haldane's rule influencing survival of the cross classes.

Development time on both host plants was assessed using the data recorded during the survival experiment. Because most of the cross classes failed to reach adulthood on one host plant or the other, the correlation between the traits was not significant, but correlations between development time and survival or weight change were all negative. Overall, Leersia-reared individuals had longer development times than rice-reared ones $(16.34 \pm 0.3$ and $20.82 \pm 1.15$ days reared on rice and Leersia, respectively; means do not include parental population development times). Development times of rice and Leersia parental populations, obtained from records taken during the crossing experiment (for rice population $=18.76 \pm 0.3$, and Leersia population $=20.0 \pm 0.78$ days), were not significantly different from each other on their natural host plant (ANOVA; MS among $=11.15 ; F_{1,28}=1.75, P>0.05$ ).

\section{Discussion}

The closest relatives of $N$. lugens, $N$. bakeri and $N$. muiri, feed on Leersia (Wilson \& Claridge, 1991), suggesting that Leersia is more likely than rice to be the ancestral host plant. A host shift has therefore occurred from Leersia to rice. DNA sequence data suggest that this shift has happened recently (probably less than $0.25 \mathrm{Myr}$ ago) and independently in Asia and Australia (Jones et al., 1996). The evidence for independent host shifts, the close proximity of 
Table 4 Estimated components of the cross mean performance for Nilaparvata lugens reared on Leersia plants using additive-dominance, non-allelic interaction, and maternal-effect models

Additive-dominance and non-allelic interaction combination

Components Six parameter Five parameter Four parameter
Maternal and Additive-dominance Additive model additive-dominance model only combination Three parameter Two parameter Five parameter

\begin{tabular}{|c|c|c|c|c|c|c|}
\hline$m$ & $-0.01 \pm 0.08$ & $-0.06 \pm 0.04$ & $0.12 \pm 0.04$ & $0.10 \pm 0.018$ & $0.03 \pm 0.008$ & $0.13 \pm 0.02$ \\
\hline$[d]$ & $0.27 \pm 0.03$ & $0.27 \pm 0.03$ & $0.21 \pm 0.02$ & $0.18 \pm 0.017$ & $0.15 \pm 0.015$ & $0.19 \pm 0.025$ \\
\hline$[h]$ & $-0.08 \pm 0.2$ & $0.06 \pm 0.05$ & $-0.16 \pm 0.05$ & $-0.14 \pm 0.03$ & - & $-0.15 \pm 0.03$ \\
\hline$[j]$ & $-0.26 \pm 0.07$ & $-0.24 \pm 0.06$ & $-0.13 \pm 0.04$ & - & - & - \\
\hline$[i]$ & $-0.21 \pm 0.08$ & $0.25 \pm 0.05$ & - & - & - & - \\
\hline$[l]$ & $0.09 \pm 0.14$ & - & - & - & - & - \\
\hline$[\mathrm{d} m]$ & - & - & - & - & - & $0.005 \pm 0.02$ \\
\hline$[\mathrm{hm}]$ & - & - & - & - & - & $-0.054 \pm 0.02$ \\
\hline Test statistics & $\chi_{3}^{2}=3.1$ & $\chi_{4}^{2}=3.57$ & $\chi_{5}^{2}=33$ & $\chi_{6}^{2}=38.09$ & $\chi_{7}^{2}=58.5$ & $\chi_{4}^{2}=\overline{27} .14$ \\
\hline$P$ & $0.5-0.3$ & $0.5-0.3$ & $<0.01$ & $<0.01$ & $<0.01$ & $<0.01$ \\
\hline
\end{tabular}

See Table 2 for abbreviations.

rice and Leersia plants throughout the range of brown planthopper, and the high potential vagility of the planthoppers (Nault \& Rodriguez, 1985), all suggest that the host shifts occurred without geographical separation of populations.

Our results are consistent with the hypothesis of recent, sympatric host shifts. The populations are now strongly adapted to their own host plants: survival on the alternate host was zero for both of our lines and adult performance was greatly reduced. However, in general the performance of the Leersia stock on rice is higher than the performance of the rice stock on Leersia. We have attempted to select lines capable of survival on the alternate host by maintaining groups of Leersia stock nymphs on rice plants, or vice versa, until the majority of nymphs have died, and then moving survivors to their own host plant. Over six generations, we

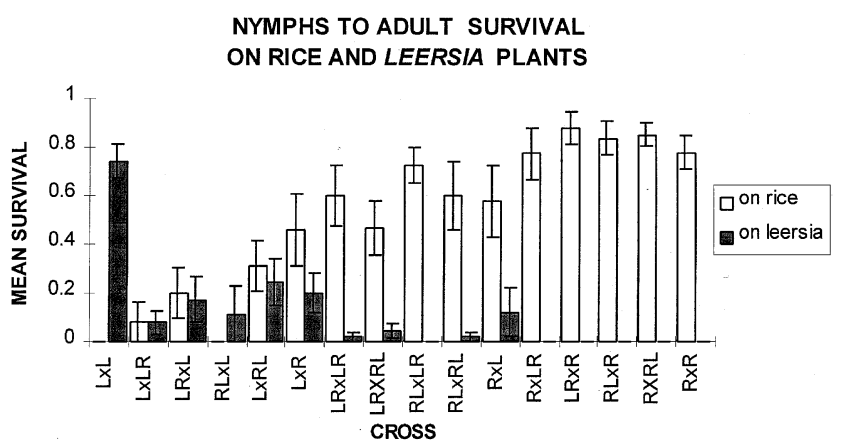

Fig. 3 Mean nymph-to-adult survival for all cross classes of Nilaparvata lugens on rice and Leersia plants. have been unable to obtain lines that can survive on the alternate host, but the Leersia nymphs selected on rice survive considerably longer than the rice nymphs on Leersia. Overall, it is easier to envisage a shift from Leersia to rice, which appears to be the more permissive host, than in the opposite direction.

The hypothesis of a recent host shift is supported by the absence of any known morphological difference between rice- and Leersia-feeding populations, although mating signals do differ (Claridge et al., 1988; Butlin, 1993, 1996; Trickett, 1995). In our data, and elsewhere (Heinrichs \& Medrano, 1984; Claridge et al., 1985), there is no evidence of postzygotic reproductive isolation through sterility or inviability (except as associated with host use), and no evidence of a Haldane effect on sex ratios.

The principal conclusion of our current analysis is that the number of loci influencing host-associated performance is small, possibly as low as one or two. This conclusion is based on a single inbred line from a single locality for each population, tested on one rice and one Leersia genotype without considering possible effects of the growth stage of the plants. More work will be needed to establish the generality of our results. However, the polygenic variation for performance on different varieties known to exist within the rice-feeding race is unlikely to influence the very different inter-racial genetic architecture.

A sympatric host shift is more likely to be associated with major gene effects, such as we observe, than with polygenic determination of performance, because selection will operate against small changes in the underlying physiological characters that are 
likely to reduce performance on the current host without enabling survival on the new host. By contrast, a mutation of large effect might enable sufficient performance on the new host to establish a population there, perhaps aided by reduced competition (Wilson \& Turelli, 1986). The probability of a dominant, or partly dominant, mutation initiating such a shift is clearly higher than for a recessive mutation and this is also consistent with our observation of dominance in favour of alleles from the rice-feeding stock. Our data suggest some epistatic interactions. This is expected following a sympatric host shift initiated by a mutation of large effect, because selection is expected to favour modifier mutations that interact with the initial major gene to perfect adaptation to the new host (Templeton, 1981).

The measure of adult performance used for the majority of our analysis has the advantage over measures such as survival or growth rate that it is less likely to be influenced by maternal effects. No significant maternal effects were detected, in contrast to some other studies (Bierbaum \& Bush, 1990; R'kha et al., 1991). Weight gain of adult females in the period immediately after ecdysis is probably a major component of fitness because it must have an impact on early fecundity. Nevertheless, it is reassuring to observe a strong correlation between this measure and survival, giving us confidence that our performance measure is a good reflection of overall host-associated adaptation. Preliminary experiments on male weight gain showed a different pattern. Males appear to feed only enough to maintain their weight, presumably spending the remainder of their time searching for mates, whereas females appear to increase weight as much as possible in the first $72 \mathrm{~h}$ of adult life, which precedes the onset of oviposition.

We expected to find essentially the same genetic architecture in our trials on Leersia as we did from trials on rice. In fact, we were unable to find any satisfactory fit to the performance data on Leersia. Inspection of the distributions of performance (Fig. 2) and survival (Fig. 3) make the reason clear. Apart from the Leersia strain itself and the backcrosses to Leersia, all cross classes lose weight on average on Leersia plants. However, weight losses of more than about $20 \%$ of initial body weight are never recorded, presumably because individuals that do lose more weight die before the second measurement. Consistent with this interpretation is the low nymph-to-adult survival of all cross classes on Leersia. Although the means and variances of performance of all cross classes except $\mathrm{L}$ and $\mathrm{BL}$ are clearly biased, the pattern is qualitatively in agreement with expectations based on the genetic model for performance on rice. With a small number of loci and directional dominance for alleles from the rice population, one expects survival and performance of the $F_{1}, F_{2}$ and $B R$ classes on Leersia to be similar to the performance of $\mathrm{R}$ on Leersia, as they are, with BL intermediate.

A sympatric host shift requires a change in host preference as well as host-associated performance. In brown planthopper, as in many phytophagous insects, female oviposition preference is the key trait because nymphs rarely move from the plant on which they hatch. Data on the inheritance of host preference will be presented elsewhere but the sympatric host shift hypothesis might be most strongly supported if host preference and host-associated performance have a common genetic basis. This is possible in an insect like brown planthopper where feeding performance is apparently strongly influenced by chemical signals received from the plant that stimulate or deter feeding (Søgawa, 1982). The same signals may stimulate or deter oviposition, or females may simply lay eggs on plants on which they choose to feed. If this is the case, a single mutation may be sufficient to alter both preference and performance. Because brown planthoppers also mate on their host plant and mate location is dependent on substrate-transmitted acoustic signals (Claridge, 1985), such a mutation would also induce assortative mating. This is probably the ideal scenario for sympatric speciation (Diehl \& Bush, 1989).

\section{Acknowledgements}

We thank Prof. M. F. Claridge and J. C. Morgan for supplying the stock populations, the staff of Grove House Experimental Gardens for providing the plant material, Tom Tregenza for comments on the manuscript, and the University of Gaziosmanpasa (Tokat, Turkey) for supporting this research. Planthoppers were maintained under license from the Ministry of Agriculture, Fisheries and Food.

\section{References}

BIERBAUM, T. J. AND BUSH, G. L. 1990. Genetic differentiation in the viability of sibling species of Rhagoletis fruit flies on host plants, and the influence of reduced hybrid viability on reproductive isolation. Entomologia exp. appl., 55, 105-118.

BUSH, G. L. 1995. Species and speciation (reply). Trends Ecol. Evol., 10, 38. 
BUtLIN, R. K. 1993. The variability of mating signals and preferences in the brown planthopper, Nilaparvata lugens. J. Insect. Behav., 6, 125-140.

BUTLIN, R. K. 1996. Co-ordination of the sexual signalling system and the genetic basis of differentiation between populations in the brown planthopper, Nilaparvata lugens. Heredity, 77, 369-377.

CLARIDGE, M. F. 1985. Acoustic behavior of leafhoppers and planthoppers: Species problems and speculations. In: Nault, L. R. and Rodriquez, J. G. (eds) The Leafhoppers and Planthoppers, pp. 103-125. Wiley, New York.

ClARIDGE, M. F., DEN HOLlANDER, J. AND MORGAN, J. C. 1985. The status of weed-associated populations of the brown planthopper, Nilaparvata lugens (Stål) - host race or biological species? Zool. J. Linn. Soc., 84, 77-90.

CLARIDGE, M. F., DEN HOLlANDER, J. AND MORGAN, J. C. 1988. Variation in host-plant relations and courtship signals of weed-associated populations of the brown planthopper, Nilaparvata lugens (Stål), from Australia and Asia: a test of the recognition species concept. Biol. J. Linn. Soc., 35, 79-93.

DEN HOLLANDER, J. AND PATHAK, P. K. 1981. The genetics of the "biotypes" of the rice brown planthopper Nilaparvata lugens. Entomologia exp. appl., 29, 76-86.

DEPRIEST, D. J. 1983. Using the singly truncated normal distribution to analyse satellite data. Commun. Statist. Theor. Math., 12, 263-272.

DIEHL, S. R. AND BUSH, G. L. 1989. The role of habitat preference in adaptation and speciation. In: Otte, D. and Endler, J. (eds) Speciation and its Consequences, pp. 345-365. Sinauer Associates, Sunderland, MA.

FUTUYMA, D. J. AND PETERSON, s. C. 1985. Genetic variation in the use of resources by insects. Ann. Rev. Ent., 30, 217-238.

Genstat 1987. genstat 5 Reference Manual. Clarendon Press, Oxford.

GULDEMOND, J. A. 1990. Evolutionary genetics of the aphid Cryptomyzus, with a preliminary analysis of the inheritance of host plant preference, reproductive performance and host-alteration. Entomologia exp. appl., 57, $65-76$.

HATChETT, J. H. AND GALlun, R. L. 1970. Genetics of the ability of the Hessian fly, Mayetiola destructor, to survive on wheats having different genes for resistance. Ann. Entomol. Soc. Am., 63, 1400-1407.

HEINRICHS, E. A. AND MEDRANO, F. G. 1984. Leersia hexandra, a weed host of the brown planthopper, Nilaparvata lugens (Stål). Crop Prot., 3, 77-85.

JAENIKE, J. 1990. Host specialization in phytophagous insects. Ann. Rev. Ecol. Syst., 21, 243-273.

JAENIKE, J. AND HOLT, R. D. 1991. Genetic variation for habitat preference: evidence and explanations. Am. Nat., 137 (suppl.), 67-90.

JONES, P. L., GACESA, P. AND BUTLIN, R. K. 1996. Systematics of brown planthopper and related species using nuclear and mitochondrial DNA. In: Symondson, W. O.
C. and Liddell, J. E. (eds) The Ecology of Agricultural Pests: Biochemical Approaches, pp. 133-148. Chapman and Hall, London.

KNERER, G. AND ATWOOD, C. E. 1972. Evolutionary trends in the subsocial sawflies belonging to the Neodiprion abietis complex (Hymenoptera: Tenthredinoidea). Am. Zool., 12, 407-418.

LANDE, R. 1981. The minimum number of genes contributing to quantitative variation between and within populations. Genetics, 99, 541-553.

MATHER, K. AND Jinks, J. L. 1982. Biometrical Genetics, 3rd edn. Chapman and Hall, London.

NAUlT, L. R. AND RODRIGUEZ, J. G. 1985. The Leafhoppers and Planthoppers. John Wiley, New York.

NORUSIS, M. J. 1993. sPSS for Windows: Base System User's Guide. SPSS, Chicago.

R'KHA, S., CAPY, P. AND DAVID, J. R. 1991. Host-plant specialization in the Drosophila melanogaster species complex: A physiological, behavioral, and genetic analysis. Proc. Natl. Acad. Sci. U.S.A., 88, 1835-1839.

RICE, W. R. AND HOSTERT, E. E. 1993. Laboratory experiments on speciation: what have we learned in 40 years? Evolution, 47, 1637-1653.

SOGAwA, K. 1982. The rice brown planthopper: Feeding physiology and host plant interactions. Ann. Rev. Ent., 27, 49-73.

TAUBER, C. A. AND TAUBER, M. J. 1989. Sympatric speciation in insects: perception and perspective. In Otte, D. and Endler, J. (eds) Speciation and its Consequences, pp. 307-343. Sinauer Associates, Sunderland, MA.

TAVORMinA, S. J. 1982. Sympatric genetic divergence in the leaf-mining insect Liriomyza brassicae (Diptera: Agromyzidae). Evolution, 36, 523-534.

Templeton, A. R. 1981. Mechanisms of speciation - a population genetic approach. Ann. Rev. Ecol. Syst., 12, 23-48.

THOMPSON, J. N. AND PELLMYR, O. 1991. Evolution of oviposition behavior and host preference in Lepidoptera. Ann. Rev. Ent., 36, 65-89.

Trickett, A. J. 1995. Sexual Selection and the Brown Planthopper, Nilaparvata lugens. Ph.D. Thesis, University of Leeds.

VIA, s. 1989. Field estimation of variation in host plant use between local populations of pea aphid from two crops. Ecol. Entomol., 14, 357-364.

VIA, s. 1990. Ecological genetics and host adaptation in herbivorous insects: the experimental study of evolution in natural and agricultural systems. Ann. Rev. Ent., 35, 421-446.

WILSON, M. R. AND ClARIDGE, M. F. 1991. Handbook for the Identification of Leafhoppers and Planthoppers of Rice. CAB International, London.

WILSON, D. S. AND TURELli, M. 1986. Stable underdominance and evolutionary invasion of empty niches. Am. Nat., 127, 835-850.

Wright, s. 1968. Evolution and the Genetics of Populations, vol. 1. Genetic and Biometrical Foundations. University of Chicago Press, Chicago. 